\title{
Effect of Soil Moisture, Soil Density, and Cone Penetrometer Material on Finite Element Prediction of Soil Hardpan Depth
}

\author{
Mehari Z. Tekeste, Graduate Research Assistant \\ Driftmier Engineering Center, University of Georgia, Athens \\ Randy L. Raper, Agricultural Engineer \\ USDA- ARS National Soil Dynamics Laboratory, Auburn, AL \\ Ernest W. Tollner, Professor \\ Driftmier Engineering Center, University of Georgia, Athens
}

Thomas R. Way, Agricultural Engineer

USDA- ARS National Soil Dynamics Laboratory, Auburn, AL

\author{
Written for presentation at the \\ 2005 ASAE Annual International Meeting \\ Sponsored by ASAE \\ Tampa Convention Center \\ Tampa, Florida \\ 17 - 20 July 2005
}

\begin{abstract}
An accurate soil hardpan determination is important for maximum precision tillage performance. Soil cone penetrometer data are often analyzed to predict soil hardpan depths. The prediction in layered soils may be limited due to the complexity of soil reaction to cone penetration. An axisymmetric finite element (FE) model was developed to investigate soil hardpan predictions and soil deformation failures on layered Norfolk sandy loam soil. The soil was considered as a non-linear elastic-plastic material modeled using a constitutive relationship from Drucker-Prager model with the Hardening option in ABAQUS, a commercially available FE package. ABAQUS/Explicit was used to solve the simulation of soil-cone contact pair interaction using a frictional property. The results showed that the FE model captured the soil cone penetration trend in layered soil with two deflection points indicating the start of the hardpan and the peak cone penetration resistance. The FE model predicted hardpan depth $(8.62 \mathrm{~cm})$ was smaller than the cone penetrometer predicted depth $(11.03$ $\mathrm{cm}$ ). Soil moisture, bulk density and cone material significantly affected the FE and cone penetrometer predicted soil hardpan depths. The simulation also showed soil deformation zones about 3 times the diameter of the cone developed around the advancing cone.
\end{abstract}

Keywords. Soil hardpan, cone penetrometer, Finite Element, soil-cone interaction.

The authors are solely responsible for the content of this technical presentation. The technical presentation does not necessarily reflect the official position of the American Society of Agricultural Engineers (ASAE), and its printing and distribution does not constitute an endorsement of views which may be expressed. Technical presentations are not subject to the formal peer review process by ASAE editorial committees; therefore, they are not to be presented as refereed publications. Citation of this work should state that it is from an ASAE meeting paper. EXAMPLE: Author's Last Name, Initials. 2005. Title of Presentation. ASAE Paper No. 05xxxx. St. Joseph, Mich.: ASAE. For information about securing permission to reprint or reproduce a technical presentation, please contact ASAE at hq@asae.org or 269-429-0300 (2950 Niles Road, St. Joseph, MI 49085-9659 USA). 


\section{Introduction}

Soil compaction impedes root growth and reduces soil aeration and water infiltration, which consequently affects crop production systems in Southeastern US soils (Raper et al., 2004). Soil compaction can be measured using a soil-cone penetrometer, an instrument that measures insertion force of a cone into the soil (ASAE, 1999a; ASAE, 1999b). As a part of site-specific soil compaction management, the depth and magnitude of the root-restricting layer, commonly referred to as soil hardpan is predicted from the cone penetrometer data analysis. The reaction of the soil to cone penetration involves a combination of cutting, compression, shear or plastic failures, or any combination of these (Gill and VandenBerg, 1968). As the cone advances into the soil, it is generally assumed that the cone penetration force estimates the relative soil strength at a particular depth. Researchers have shown that the point cone penetration force is influenced by the soil properties in the zone of influence (Gill, 1968; Sanglerat, 1972; Mulqueen et al., 1977; Lunne et al., 1997; and Susila and Hryciw, 2003). According to Lunne et al. (1997), the zone of influence depends on layering and soil material stiffness that it can reach up to 10 to 20 times the cone diameter for stiff soil material. Mulqueen et al. (1977) and Gill (1968) had also shown that a soil wedge formed in front of the cone could erroneously increase the cone index reading.

Associated with a complex soil - cone penetrometer interaction, errors could occur in interpreting cone force - depth data that could affect the accuracy of soil hardpan detection for precision tillage. In using soil cone penetrometer to detect soil hardpan depths, a study on the dynamic response of soil to cone penetration is important to evaluate the versatility of the tool in precision tillage applications. Various approaches (Farrell and Greacen, 1965; and Rohani and Baladi, 1981; and Yu and Mitchel, 1998) have been considered to study the soil mechanical responses during soil cone penetration including (1) bearing capacity theory; (2) cavity expansion theory; (3) steady state deformation; (4) finite element (FE) analysis; and (5) laboratory experimental methods. Most of these approaches used analytical methods whereby first a certain shape of soil failure surface was assumed and then limit equilibrium of forces over the soil-tool system were solved. Analytical approaches could have limitations to explain soil dynamic responses in cone penetration especially in layered and non-homogenous soil conditions because of the difficulty in pre-defining the soil failure shape and complexity of force equilibrium analysis.

With the availability of powerful PC computation speeds and FE packages that contain advanced material models, the FE method can be implemented in solving the soil cone penetration problem. FE analysis was previously used to model soil cone penetration with limited success (Markauskas et al., 2002 and Foster et al., 2005). Markauskas et al. (2002) used static elastic-plastic small strain FE analysis on sandy and clayey soils with Mohr-Columb and Tresca yield criteria, respectively. The simulation modeled a cone (60-deg and diameter, $d$ $=35.7 \mathrm{~mm})$ displacement $(\mathrm{u})$ of $0.2 \mathrm{~d}$. They also determined numerically the vertical $(\mathrm{H}=11.2 \mathrm{~d})$ and horizontal $(D=35 d)$ dimensions of the zone influenced during cone penetration. The small strain assumption as opposed to the large deformation property of soil material was a problem in their analysis. The authors have not attempted to compare the FE predicted forces with an experimentally measured cone penetration resistance. Soil cone penetration in a sandy loam and a clay loam soil was also modeled using the MSC/DYTRAN FE software by Foster et al. (2005). Their constitutive material parameters were estimated using the National Soil Dynamics Laboratory and Auburn University (NSDL-AU) soil compaction model. The FE force predicted for both soil types appeared to capture the general trend of measured cone force data but the predicted force values had large fluctuations. Statistical comparisons were not carried out with the experimentally measured soil cone penetration resistance forces to evaluate the performance of the FE analysis. 
Research on FE analysis is, thus, needed to explain the soil failure pattern in cone penetration and evaluate the FE method in predicting the magnitude and depth of soil hardpan as influenced by soil factors (soil moisture content and bulk density) and cone material properties in layered soils.

Our understanding of soil hardpan layer prediction could be improved for Norfolk sandy loam soil as a soil drying front moves downward in conditions similar to field soils by studying the soil response to cone penetration using the FE method.

Therefore, our objectives were, to:

- $\quad$ Develop FE procedure for soil cone penetration, and

- $\quad$ Determine the effects of soil moisture content and bulk density on FE predicted magnitude and depth of soil hardpan.

\section{Materials and Methods}

\section{Material Parameters for Soil Constitutive Model}

Soil was assumed as a continuum non-linear elastic-plastic material that exhibited material hardening. The soil constitutive relationship was defined using the linear form of the extended Drucker-Prager material model with a material hardening option (ABAQUS, 2004). The extended Drucker-Prager model has the capability to model frictional materials such as soil in which compressive yield strength was greater than the tensile strength and exhibited pressuredependent yield. The Drucker-Prager model has been commonly used to solve soil tillage (soiltool interaction) problems (Mouazen and Ramon, 2002 and Upadhyaya et al., 2002). The linear Drucker-Prager form requires bulk density $(\rho)$, Young's modulus (E), Poisson's ratio ( $v)$, angle of internal friction $(\phi)$, yield stress ratio in triaxial tension to triaxial compression $(\mathrm{K})$ and dilation angle $(\psi)$ for the plastic flow. Typical values of $K$ are $0.778 \leq K \leq 1.0$ (ABAQUS, 2004). A value of $\mathrm{K}=1$ was assumed during the analysis which implied that the yield surface was the von Mises circle in a deviator principal stress plane. In the associated plastic flow of the linear model, $\psi=\beta$ where $\tan (\beta)$ was the slope in the deviator stress plane. A dilation angle $(\psi)$ of $38^{0}$ was estimated from the octahedral shear stress versus octahedral normal stress of the NSDL-AU soil compaction model. A constant Poisson's ratio of 0.3 was assumed in the analysis. The NSDL-AU constitutive soil model that was developed for compactable agricultural soils subjected to different stress paths under unsaturated soil conditions was used to estimate soil mechanical parameters and the tabular data for the Drucker-Prager Hardening option. The soil mechanical parameters of NSDL-AU model are shown in table 1.

According to Bailey and Johnson (1989 and 1996), the stress-strain relationship of the NSDLAU soil compaction model was defined using:

$$
\bar{\varepsilon}_{\mathrm{v}}^{-}=\left(\mathrm{A}+\mathrm{B} \sigma_{\text {oct }}\right)\left(1-\mathrm{e}^{-\mathrm{C} \sigma_{\text {oct }}}\right)+\mathrm{D}\left(\tau_{\text {oct }} / \sigma_{\text {oct }}\right)
$$

Where the natural volumetric strain was defined as:

$$
\varepsilon_{\mathrm{v}}=\ln \left(\mathrm{V} / \mathrm{V}_{\mathrm{o}}\right)=\ln \left(\rho_{\mathrm{o}} / \rho\right)
$$


Where:

$\varepsilon_{\mathrm{v}}=$ natural volumetric strain.

$\sigma_{\text {oct }}=$ octahedral or mean normal stress $\left[\sigma_{\text {oct }}=\left(\sigma_{1}+\sigma_{2}+\sigma_{3}\right) / 3\right]$.

$\tau_{\text {oct }}=$ octahedral shear stress $\left[\tau_{\text {oct }}=\left[\left(\sigma_{1}-\sigma_{2}\right)^{2}+\left(\sigma_{2}-\sigma_{3}\right)^{2}+\left(\sigma_{1}-\sigma_{3}\right)^{2}\right]^{1 / 2} / 3\right]$.

$\mathrm{V}=$ volume at stress state.

$\mathrm{V}_{\mathrm{o}}=$ initial volume.

$\rho=$ dry bulk density at stress state.

$\rho_{\mathrm{o}}=$ initial dry bulk density.

$A, B, C$ and $D$ were compactibility coefficients for a specific soil at a specific moisture content.

Bailey and Johnson (1989 and 1996) also assumed a linear relationship between the total natural volumetric strain and the natural plastic volumetric strain according to:

$$
\mathrm{d}_{\mathrm{v}}^{-p}=\alpha \stackrel{-}{\mathrm{d} \varepsilon_{\mathrm{v}}}
$$

Where: $\varepsilon_{\mathrm{v}}^{-p}=$ natural plastic volumetric strain. $\alpha=$ constant.

The coefficients of the NSDL-AU soil model (eq. 1) for Norfolk sandy loam soil was developed at specific soil moisture content $(6.3 \%$ d.b.). Modification of the stress-strain relationship was needed to account for different soil moisture contents. Johnson (personal communication, October 2004) suggested a relationship between the bulk density ratios of triaxial tests and Proctor Density curves. He proposed that the ratio of bulk density at soil moisture content $(6.3 \%$ d.b.) to a bulk density at different soil moisture content of the same tri-axial stress test may be related to the bulk density ratios estimated from the Proctor Density curve at the corresponding soil moisture content. Mathematically the ratio of bulk density is expressed as:

$$
\left[\frac{\rho_{x}}{\rho_{i}}\right]_{\sigma} \propto f\left\{\left[\frac{\rho_{x}}{\rho_{i}}\right]_{P D}\right\}
$$

Where:

$\left[\frac{\rho_{x}}{\rho_{i}}\right]_{\sigma}=$ Dry bulk density ratios at tri-axial stress state for new soil moisture content $(\mathrm{x})$ to soil moisture content (i) of $6.3 \%$ d.b.

$\left[\frac{\rho_{x}}{\rho_{i}}\right]_{P D}=$ Dry bulk density ratios from Proctor Density curve for new soil moisture content $(\mathrm{x})$ to soil moisture content (i) of $6.3 \%$ d.b.

The relationship in equation (5) was evaluated using data from triaxial tests (Bailey, 2004) and from a Proctor Density curve (Grisso, 1985). A linear relationship of observed dry bulk density and predicted dry bulk density $\left(\rho_{x}\right)$ for the Norfolk sandy loam soil was statistically tested using SAS (SAS. Release 8.02 SAS Institute Inc., Cary, NC, 2001). Based on the bulk density ratio 
relationships, the natural volumetric strain values for different soil moisture contents were estimated using;

$$
\varepsilon_{\mathrm{v} x}^{-}=\varepsilon_{\mathrm{v}}^{-}+\ln \left(\frac{\rho_{i}}{\rho_{x}}\right)_{P D}
$$

Where: $\varepsilon_{\mathrm{v}_{X}}^{-}=$Natural volumetric strain at new soil moisture content $(\mathrm{x})$.

Tabular data of hydrostatic yield stress vs. volumetric plastic strain for the Drucker-Prager Hardening option was determined from the natural volumetric stress-strain relationship (eq. 6). The relationship defined in equation (4) was used to obtain the volumetric plastic strain values for the tabular data. Tangential Young's modulus values were estimated from the stress-strain graphs. The mean of the estimated tangential Young's modulus was used in the FE analysis. The wet bulk density and soil moisture contents were obtained from experiments conducted in a soil column. The soil layers varied in wet bulk density and soil constitutive material parameters.

\section{FE Problem Formulation and Procedures}

FE analysis of an axisymmetric soil cone penetration problem was carried out using ABAQUS commercially available software (ABAQUS, 2004). The FE analysis was performed in three stages: pre-processing and post-processing using ABAQUS/CAE, and simulation using ABAQUS/Explicit. The ABAQUS/CAE environment comprised modules that interacted with ABAQUS/Explicit and performed the preprocessing stage including the FE geometry, specification of material properties, assembling the geometries, defining analysis steps and surface interactions, loading, boundary conditions and mesh generation. The ABAQUS/Explicit was a valuable method for quasi-static dynamic analysis and solved contact problems such as the soil cone penetration at a reduced computational time. The outputs and visualization of results were monitored in the post processing stage using the visualization module of ABAQUS/CAE.

The model was separated into two bodies, a deformable soil and a rigid cone (Fig. 1). The soil had a radius of $10.6 \mathrm{~cm}$ and was $22.9 \mathrm{~cm}$ in height. The soil body was partitioned into three layers varying in thickness similar to the soil column study: above $(5.08 \mathrm{~cm})$, within $(2.54 \mathrm{~cm})$ and below (15.2 $\mathrm{m}$ ) soil hardpan. For each soil layer, there were separate material constitutive parameters and a table of hydrostatic yield stress vs. volumetric plastic strain. The entire soil body was meshed using a 4-node bilinear axisymmetric quadrilateral shell element with a reduced integration and hourglass control (CAX4R). The entire soil body was seeded with equal edge mesh size ( $0.5 \mathrm{x}$ cone radius). A mesh size of the soil brick elements was smaller than the cone radius to meet the master-slave surface contact algorithm in ABAQUS/ Explicit. The boundaries on the right and bottom edges of the axisymmetric soil model were constrained in the radial (U1) and vertical (U2) transitional degrees of freedom respectively (Fig. 1). The top soil surface where the cone penetrates was not constrained.

The cone $\left(30^{\circ}\right.$ and base diameter, $\left.\mathrm{d}=1.28 \mathrm{~cm}\right)$ was defined as a discrete rigid body elastic material (Young's modulus, $E=193050 \mathrm{MPa}$ and Poisson's ratio, $v=0.3$ ) and modeled by a 2node linear axisymmetric element (RAX2). A reference node was attached at the center of mass of the cone to govern the motion of the cone. Displacement $(\mathrm{U} 2=-12.0 \mathrm{~cm})$ was prescribed at the reference node to simulate the cone penetration rate of $1.65 \mathrm{~cm} / \mathrm{s}$. A similar insertion rate was used when taking soil cone penetration readings in the laboratory for the FE model verification. The machine (Sintech/2G) that was used to insert the soil cone penetrometer supported a maximum rate of $1.69 \mathrm{~cm} / \mathrm{s}$. The shaft of the soil cone penetrometer was not included in the model because it is generally assumed that the force contribution from the shaft is small. The soil-cone interaction was simulated by element based surface pair contact 
between the rigid cone body (master surface) and the deformable soil (slave surface) with a friction property. Stainless steel (Metal), Teflon coated stainless steel (TMetal) and Teflon cone materials were modeled by specifying different values of soil-tool coefficient of friction. The cone motion was constrained from moving to the radial direction.

Stress and strain variables were requested at $0.001 \mathrm{~s}$ intervals. The resultant contact forces between the cone and the soil layers and a vertical displacement (U2) of the referenced node were also requested to simulate the cone penetration forces and displacement.

\section{Experiment for verification of FE prediction of Soil Hardpan Attributes}

A soil cone penetration experiment was conducted to verify the FE prediction of soil hardpan attributes. Soil for the experiment was obtained from the Norfolk sandy loam (Typic Paleudults) soil bin in the NSDL in Auburn, AL. The Norfolk sandy loam particle size distribution was $72 \%$ sand, $17 \%$ silt and $11 \%$ clay (Batchelor, 1984). Two millimeter sieved soil samples were brought to a soil moisture content of $5 \% \mathrm{~d}$. b. and kept in tight plastic bags for a least a week to equilibrate the soil moisture. Three layers of soil [above, within and below the soil hardpan] that varied in bulk density were created in a cylinder $(20 \mathrm{~cm}$ diameter $X 28 \mathrm{~cm}$ height $)$ by applying axial loading using a rigid cylinder piston. The experiment was carried out using a split plot design with three replicates. Bulk density (within hardpan) was a main plot treatment. Soil moisture was a subplot treatment. Cone material type was a sub-sub plot treatment. The soil column samples were first wetted to near saturation and put in a greenhouse located at the NSDL until the soil moisture content measured using tensiometers at the hardpan depth reached $10 \mathrm{kPa}$ (soil moisture level I) and $60 \mathrm{kPa}$ (soil moisture level II) soil moisture suction. Once the soil samples reached the target soil moisture levels, cone penetration readings were taken using soil cone penetrometer with a randomly selected cone material of Metal, TMetal and Teflon.

A separate experiment was conducted with three replicates to determine the soil-tool [Metal, TMetal and Teflon] coefficients of friction according to the Coulomb friction criterion. Soil samples ( $2 \mathrm{~mm}$ sieved) equilibrated to $5 \%$ and $10 \%$ (d.b.) soil moisture contents were filled in a wooden box. For each soil moisture content, the soil was compressed to two bulk densities (1.22 and $\left.1.67 \mathrm{Mg} \mathrm{m}^{-3}\right)$. A bar $(0.6 \mathrm{~cm}$ thickness, $15 \mathrm{~cm}$ length and $15 \mathrm{~cm}$ width) made of Teflon, Stainless Steel and Teflon-coated steel was laid on top of the soil. For the Teflon coated stainless steel, dry powder Teflon (® Fluorotelometer powder) was sprayed on a stainless steel piece and dried before taking a measurement. The pull force required to slide the bar in the soiltool interface with a normal weight of 2,11 and $22 \mathrm{~kg}$ on top of the bar was measured using a load cell. The coefficients of soil-material friction were determined by estimating the slope of a linearly fitted line to the normal force vs. average sliding force data.

\section{Data Analysis}

Treatment effects of soil moisture, bulk density and cone material on FE prediction of the magnitude and depth of a soil hardpan were analyzed using appropriate statistical procedures in SAS (SAS. Release 8.02 SAS Institute Inc., Cary, NC, 2001). Similarly, FE predications of the soil hardpan were compared with the soil cone penetrometer data analysis method. An F-test statistic with an alpha $(\alpha)$ level of 0.05 was used for all treatment and method comparisons.

\section{Results and Discussion}

The bulk density within the hardpan was used to classify the three compaction treatments, namely compaction I, compaction II and compaction III. The bulk density in the compaction II 
and compaction III treatments were significantly greater than the above and below hardpan positions $(P<0.0001)$. To investigate the effects of soil parameters on FE prediction, statistical analyses were performed for only the compaction II (1.64 $\mathrm{Mg} \mathrm{m}^{-3}$, within soil hardpan) and compaction III (1.71 $\mathrm{Mg} \mathrm{m}^{-3}$, within soil hardpan) because no statistical variations in bulk density values were observed among the soil layers for compaction I.

A linear relationship was observed between the predicted bulk density from equation (5) and the observed bulk density from tri-axial stress test with high correlation coefficient $\left(r^{2}=0.96\right)$ and 99 $\%$ confidence intervals of $[-0.13559,0.02273]$ and $[0.96768,1.06866]$ for the intercept and slope, respectively. For the FE analysis, the bulk density values (Table 2 ) that were obtained in the soil column study were used for the bulk density $\left(\rho_{x}\right)$ in equation (6) to determine the natural volumetric strains. The stress-strain relationships for the three layers of the threecompaction treatments were shown in figure 2 . The differences in bulk density values were manifested in the stress-strain relationships. The natural volumetric strains for the within hardpan layer were smaller than the above and below hardpan (Fig. 2 (B and C)). Tangential Young's modulus values were estimated from each of the curves in figure 3 . The mean value of the tangential Young's modulus for each soil layer was estimated for use in the FE analysis.

\section{Soil Hardpan Attributes Prediction using Cone Penetrometer and Finite Element}

The FE simulation had a similar trend to the penetration resistance forces of the cone penetrometer readings (Figs. 3 and 4). The FE predicted contact forces had oscillatory responses typically occurring in ABAQUS/ Explicit simulation. A moving average filtering technique was performed on the FE data to remove noise. After data smoothing, the FE trend showed two deflection points, one near the start of the soil hardpan and another one near the peak cone penetration force. For most treatment conditions, contact forces obtained with the FE analysis overestimated and underestimated the soil cone penetration resistance forces for soil moisture level II (4.17\% d.b.) and level I (8.78\% d.b.), respectively (Figs. 3 and 4). FE force data values observed in this study appear to be similar to the force data reported by Foster et al. (2005) for Norfolk sandy loam soil. The large differences in the FE force values and cone penetrometer data could possibly be due to the fact that the FE model may not account for all soil failure modes (shear, tensile and cutting) that occurred during cone penetration because the soil constitutive model used in the analysis incorporated only the hydrostatic compaction behavior. A constant Poisson's ratio assumption may also be another possible reason for the differences.

Results for the depth to the peak cone penetration forces predicted by the FE method and cone penetrometer were statistically compared. The FE predicted soil hardpan depths $(8.62 \mathrm{~cm})$ smaller than the cone penetrometer method $(11.03 \mathrm{~cm})(P<0.0001)$.

The influences of soil parameters on the prediction of soil hardpan depths were analyzed separately for FE and cone penetrometer methods. In both methods, the peak or the deflection point in the force readings occurred below the soil hardpan thickness measured in the laboratory experiment (Table 5, depth to the top hardpan + hardpan thickness). The soil moisture content and cone material strongly affected the cone penetrometer prediction of soil hardpan depths. There were no interaction effects of soil moisture content and cone material on the predicted depths. The mean soil hardpan depth in the wet soil condition $(8.78 \%$ d.b.) was $11.01 \mathrm{~cm}$ and in the dry $(4.17 \%$ d.b. $)$ the depth was $8.32 \mathrm{~cm}$. Varying the coefficient of soil-tool frictions (Table 4) also affected the soil hardpan depth prediction with the depth from the cone made from Metal $(7.19 \mathrm{~cm})$ being shallower than TMetal $(9.96 \mathrm{~cm})$ and Teflon $(11.86 \mathrm{~cm})(P<$ $0.0001)$. When a Teflon cone was used, the predicted depth increased by $65 \%$ as compared to the ASAE standard stainless steel (Metal) cone. 
Similarly the FE predicated soil hardpan depths were affected by the soil moisture contents, soil bulk density, cone material and their interactions $(P<0.0001)$. The FE predicted depth for the dry soil moisture conditions $(9.14 \mathrm{~cm})$ was greater than for the wet soil moisture conditions $(7.54$ $\mathrm{cm})$. This was contrary to the cone penetrometer prediction of the soil hardpan depth that soil drying decreased the predicted depth. The reason for this was not determined. The FE predicted soil hardpan depths varied statistically by the soil-tool friction property (Teflon 8.68 $\mathrm{cm}$, Metal $8.27 \mathrm{~cm}$, TMetal $8.07 \mathrm{~cm}$ ).

\section{Stress and soil deformation patterns}

The FE results showing the soil responses to the cone penetration are shown in figure 5 ( $A$ and $B)$. The element on the surface rose up as the cone advanced into the soil. The stress concentration near the rigid cone body was highest near the cone and decreased as the radial distance from the cone increased. The stress and deformation distribution showed the effect of friction that as the coefficient of friction for metal cone was used, the stress and plastic strain ranges were higher as compared to the range for soil-teflon and soil-Tmetal (figure not shown). The plastic zone extended nearly three times the diameter of the cone suggesting that the cone penetration resistance force was a measure of soil reaction within the zone of influence.

\section{Conclusions}

From the finite element analysis of cone penetration on Norfolk sandy loam soil in predicting soil hardpan, the following conclusions were drawn.

1). The finite element procedure was successfully developed in ABAQUS to simulate soil cone penetration in a layered Norfolk sandy loam soil that varied values in soil moisture content and bulk density.

$2)$. In both the FE and cone penetrometer methods, when metal was used $\left(\mu_{\text {soil-metal }}=0.50\right)$ the predicted depth was shallower than when Teflon $(\mu$ soil-Teflon $=0.31)$ cone material was used.

$3)$. In dry soil moisture condition ( $4.17 \%$ d.b.), the soil hardpan was predicted at shallower depth using a cone penetrometer than at wet soil moisture condition $(8.78 \%$ d. b.).

4). Use of a finite element analysis that accounts for the confining and shearing stresses of the NSDL-AU soil model and assuming variable Poisson's ratio may further improve the prediction of cone penetration force values.

\section{Acknowledgements}

The authors would like to acknowledge the contribution of Dr. Clarence Johnson of Auburn University and Dr. Alvin Bailey of the USDA-ARS-NSDL at Auburn, AL for their suggestion on NSDL-AU soil compaction model modifications and provision of tri-axial stress data. 
Table 1. Mean initial conditions and NSDL-AU soil compaction model coefficients for Norfolk sandy loam soil.

\begin{tabular}{|c|c|c|c|c|c|c|c|c|c|}
\hline & $\begin{array}{c}\text { Soil } \\
\text { moisture } \\
(\% \text { d.b. })\end{array}$ & $\begin{array}{l}\text { Initial bulk } \\
\text { density } \\
\left(\mathrm{Mg} \mathrm{m}^{-3}\right)\end{array}$ & $\begin{array}{c}\text { Poisson's } \\
\text { ratio } \\
v \\
\end{array}$ & $\begin{array}{l}\text { Soil-soil coefficient } \\
\text { of friction } \\
(\mu \text { soil-soil })\end{array}$ & $A^{[a]}$ & $\begin{array}{c}\mathrm{B} \\
\left(\mathrm{kPa}^{-1}\right)\end{array}$ & $\begin{array}{c}\mathrm{C} \\
\left(\mathrm{kPa}^{-1}\right)\end{array}$ & $\bar{D}$ & $\alpha^{[b]}$ \\
\hline Value & 6.3 & 1.35 & 0.3 & 0.58 & -0.241 & -0.0002 & 0.0126 & -0.1122 & 0.926 \\
\hline
\end{tabular}

[a] A, B, C and D are model coefficients for the NSDL-AU soil compaction model from Bailey and Johnson (1989).

[b] $\alpha$ is the slope of a straight regression line fit to data in a graph of the plastic natural volumetric strain graphed as a function of total natural volumetric strain, from Foster et al. (2005).

Table 2. Dry bulk density from the laboratory experiment at three positions (above, within and below the hardpan) for three compaction levels of Norfolk sandy loam soil.

\begin{tabular}{|c|c|c|c|c|c|c|c|c|c|}
\hline & \multicolumn{3}{|c|}{ Compaction I } & \multicolumn{3}{|c|}{ Compaction II } & \multicolumn{3}{|c|}{ Compaction III } \\
\hline & Mean & SD & $\begin{array}{c}95 \% \text { Confidence } \\
\text { Interval }\end{array}$ & Mean & SD & $\begin{array}{c}95 \% \text { Confidence } \\
\text { Interval }\end{array}$ & Mean & SD & $\begin{array}{c}95 \% \text { Confidence } \\
\text { Interval }\end{array}$ \\
\hline Above & 1.32 & 0.08 & $1.28-1.36$ & 1.27 & 0.09 & $1.22-1.31$ & 1.27 & 0.08 & $1.23-1.31$ \\
\hline Within & 1.32 & 0.09 & $1.28-1.36$ & 1.64 & 0.11 & $1.59-1.68$ & 1.71 & 0.09 & $1.66-1.75$ \\
\hline Below & 1.25 & 0.04 & $1.23-1.27$ & 1.48 & 0.06 & $1.46-1.51$ & 1.54 & 0.06 & $1.51-1.57$ \\
\hline
\end{tabular}

Table 3. Soil moisture at three positions (above, within and below the hardpan) at the two soil moisture levels and three compaction levels of Norfolk sandy loam soil.

\begin{tabular}{|c|c|c|c|c|c|c|c|c|c|c|c|c|}
\hline & \multicolumn{6}{|c|}{ Soil Moisture Level I } & \multicolumn{6}{|c|}{ Soil Moisture Level II } \\
\hline & \multicolumn{6}{|c|}{ Compaction I Compaction II Compaction III } & \multicolumn{2}{|c|}{ Compaction I } & \multicolumn{4}{|c|}{ Compaction II Compaction III } \\
\hline & Mean & SD & Mean & SD & Mean & SD & Mean & SD & Mean & SD & Mean & SD \\
\hline & & & & & & & & & & & & --- \\
\hline Above Hardpan & 6.20 & 1.94 & 6.08 & 1.95 & 7.72 & 1.38 & 2.47 & 0.30 & 3.02 & 0.32 & 2.40 & 0.15 \\
\hline Within Hardpan & 8.08 & 1.53 & 8.08 & 2.22 & 9.25 & 1.40 & 4.41 & 0.55 & 4.97 & 0.21 & 3.83 & 0.23 \\
\hline Below Hardpan & 10.26 & 3.08 & 9.53 & 3.25 & 10.31 & 1.99 & 5.05 & 0.79 & 5.43 & 0.26 & 4.21 & 0.26 \\
\hline
\end{tabular}

Table 4. Coefficient of friction for soil - cone materials (Metal, TMetal and Teflon) at two soil moisture contents and bulk densities of Norfolk sandy loam soil.

\begin{tabular}{|c|c|c|c|c|c|c|c|}
\hline \multirow{2}{*}{$\begin{array}{c}\text { Soil Moisture } \\
\text { (\% d.b.) }\end{array}$} & \multirow{2}{*}{$\frac{\text { Bulk Density }}{\left(\mathrm{Mg} \mathrm{m}^{-3}\right)}$} & \multicolumn{5}{|c|}{------SSoil -Tool Friction Property } & \multirow{2}{*}{$\begin{array}{c}-\cdots \\
\mathrm{SD}\end{array}$} \\
\hline & & $\mu_{\mathrm{m} \text { etal }}$ & SD & $\mu$ тмetal & SD & $\mu$ т eflon & \\
\hline \multirow[t]{2}{*}{5} & 1.22 & 0.37 & 0.03 & 0.27 & 0.03 & 0.33 & 0.01 \\
\hline & 1.67 & 0.51 & 0.05 & 0.36 & 0.01 & 0.31 & 0.02 \\
\hline \multirow[t]{2}{*}{10} & 1.22 & 0.49 & 0.01 & 0.29 & 0.03 & 0.31 & 0.01 \\
\hline & 1.67 & 0.62 & 0.01 & 0.35 & 0.04 & 0.3 & 0.01 \\
\hline
\end{tabular}


Table 5. Actual depth to the top of the hardpan, hardpan thickness and below hardpan measured in soil layers in soil column.

\begin{tabular}{|c|c|c|c|c|c|c|c|c|c|}
\hline & \multicolumn{3}{|c|}{ Compaction I } & \multicolumn{3}{|c|}{ Compaction II } & \multicolumn{3}{|c|}{ Compaction III } \\
\hline & \multirow[b]{2}{*}{ Mean } & \multicolumn{2}{|c|}{$95 \%$ Confidence } & \multirow[b]{2}{*}{ Mean } & \multicolumn{2}{|c|}{$95 \%$ Confidence } & \multirow[b]{2}{*}{ Mean } & \multicolumn{2}{|c|}{$95 \%$ Confidence } \\
\hline & & SD & Interval & & SD & Interval & & SD & Interval \\
\hline Depth to Top Hardpan & 2.53 & 0.15 & $2.46-2.60$ & 5.15 & 0.48 & $4.92-5.36$ & 5.28 & 0.4 & $5.08-5.48$ \\
\hline Hardpan Thickness & 5.07 & 0.34 & $4.92-5.22$ & 4.09 & 0.28 & $3.97-4.22$ & 3.92 & 0.22 & $3.81-4.03$ \\
\hline Below Hardpan & 18.67 & 0.59 & 18.39-18.94 & 15.87 & 1.12 & $15.36-16.38$ & 15.19 & 0.56 & $14.91-15.47$ \\
\hline
\end{tabular}

Table 6. Cone penetrometer and FE predicted soil hardpan depth.

\begin{tabular}{|c|c|c|c|c|c|c|c|c|c|}
\hline & \multicolumn{5}{|c|}{ Cone penetrometer predictedeak depth $(\mathrm{cm})$} & \multicolumn{4}{|c|}{ FE predicted peak depth $(\mathrm{cm})$} \\
\hline & \multicolumn{2}{|c|}{ Metal } & \multicolumn{2}{|c|}{ Tmetal } & \multicolumn{2}{|c|}{ Teflon } & \multirow{2}{*}{$\begin{array}{l}\text { Metal } \\
\text { Mean }\end{array}$} & \multirow{2}{*}{$\begin{array}{l}\text { Tmetal } \\
\text { Mean }\end{array}$} & \multirow{2}{*}{$\begin{array}{l}\text { Teflon } \\
\text { Mean }\end{array}$} \\
\hline & Mean & SD & Mean & SD & Mean & SD & & & \\
\hline Soil Moisture Level I Compaction I & 6.32 & 2.42 & 12.64 & 1.76 & 13.74 & 0.72 & 11.3 & 11.8 & 11.3 \\
\hline \multirow[t]{2}{*}{ (8.78 \% d. b.) } & 9.06 & 1.37 & 10.31 & 1.39 & 13.42 & 0.72 & 6.82 & 7.09 & 7.76 \\
\hline & 7.06 & 2.62 & 11.99 & 2.71 & 14.26 & 0.1 & 7.36 & 7.63 & 8.57 \\
\hline \multirow{3}{*}{$\begin{array}{l}\text { Soil Moisture Level II } \\
(4.17 \% \text { d. b.) }\end{array}$} & 11.63 & 1.91 & 9.72 & 0.89 & 8.88 & 0.15 & 6.28 & 7.09 & 7.36 \\
\hline & 6.36 & 0.04 & 8.54 & 0.23 & 10.01 & 0.63 & 9.66 & 9.12 & 9.12 \\
\hline & 6.28 & 1.41 & 8.99 & 0.35 & 9.75 & 0.67 & 9.25 & 8.44 & 9.25 \\
\hline
\end{tabular}

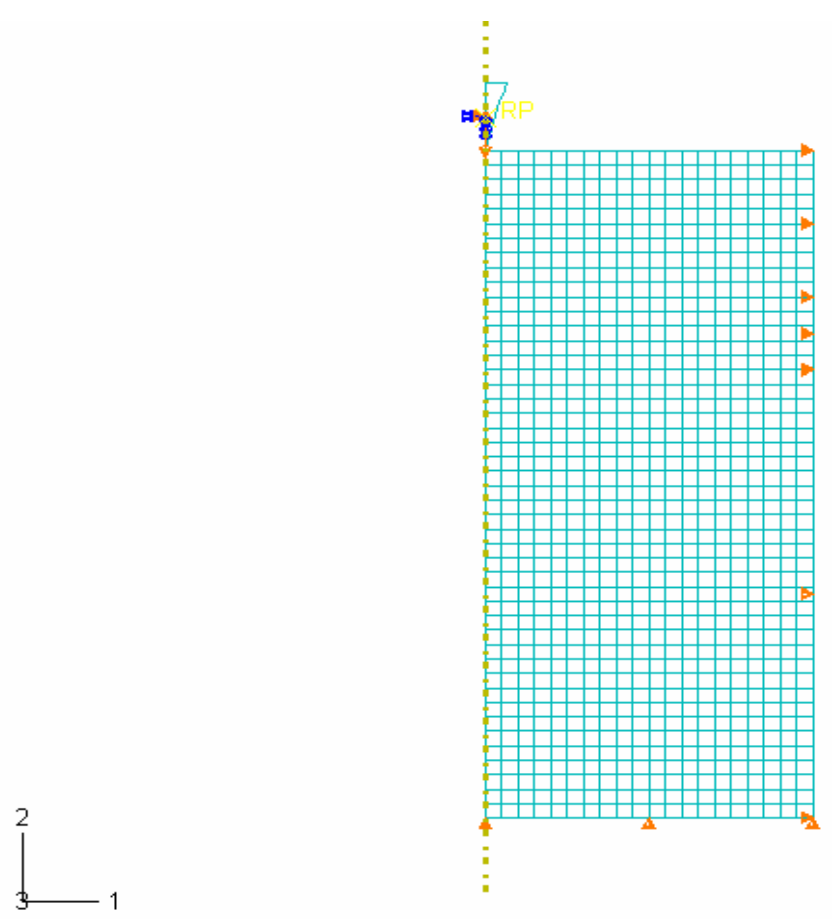

Figure1. Two-dimensional FEM mesh of the soil and the cone. The arrows indicate boundary conditions that constraint the translational degrees of freedom of the left and bottom edges of the soil and governing the vertical motion of the cone. 


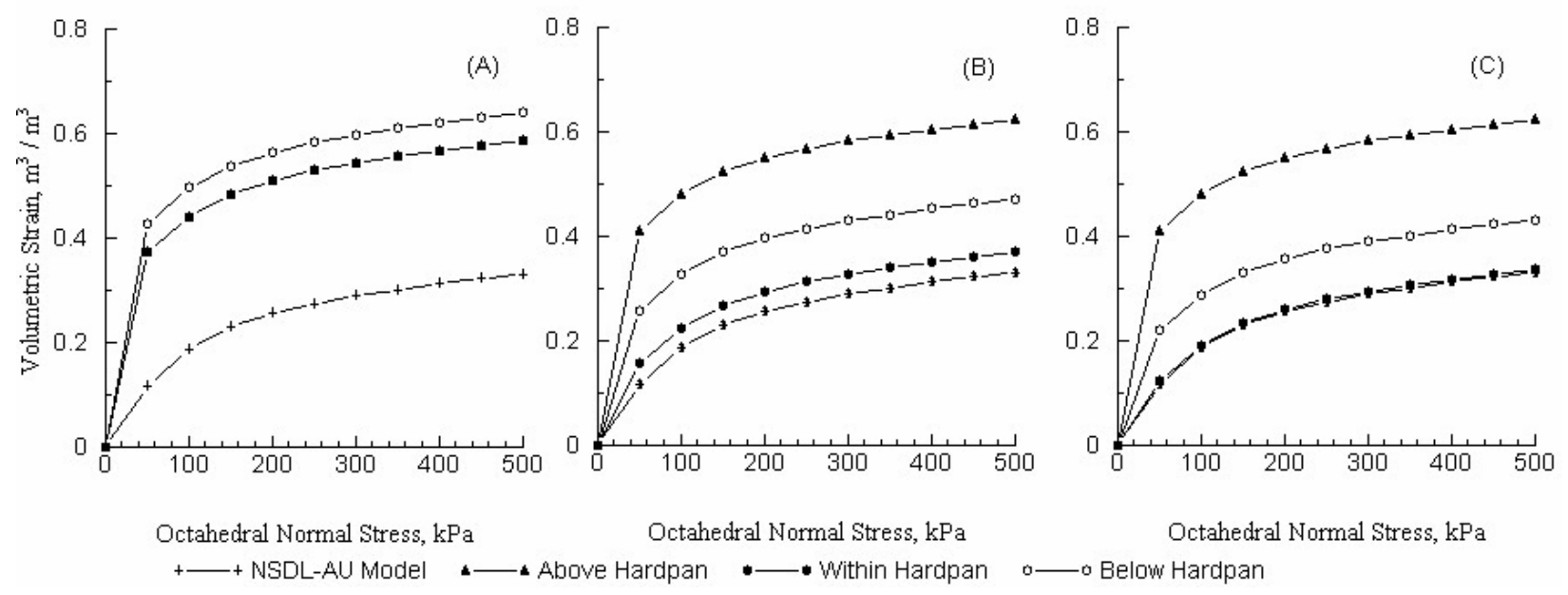

Figure 2. Natural volumetric strains vs. octahedral stress for compaction I (A), compaction II (B) and compaction III (C) and the three soil layer positions (Above, within and below hardpan).

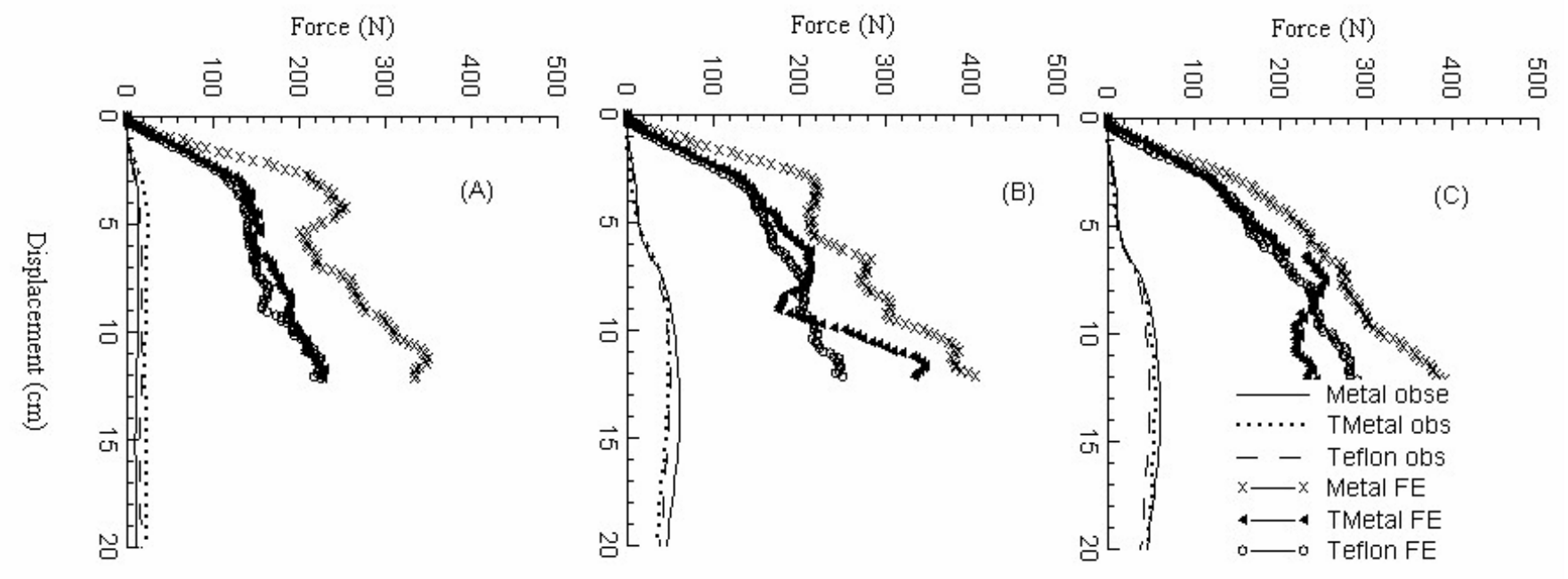

Figure 3. FE predicted versus (line and symbols) observed penetration resistance forces (lines) for soil moisture level I (Wet) and for compaction I (A), compaction II (B) and compaction III (C) and cone material types. 


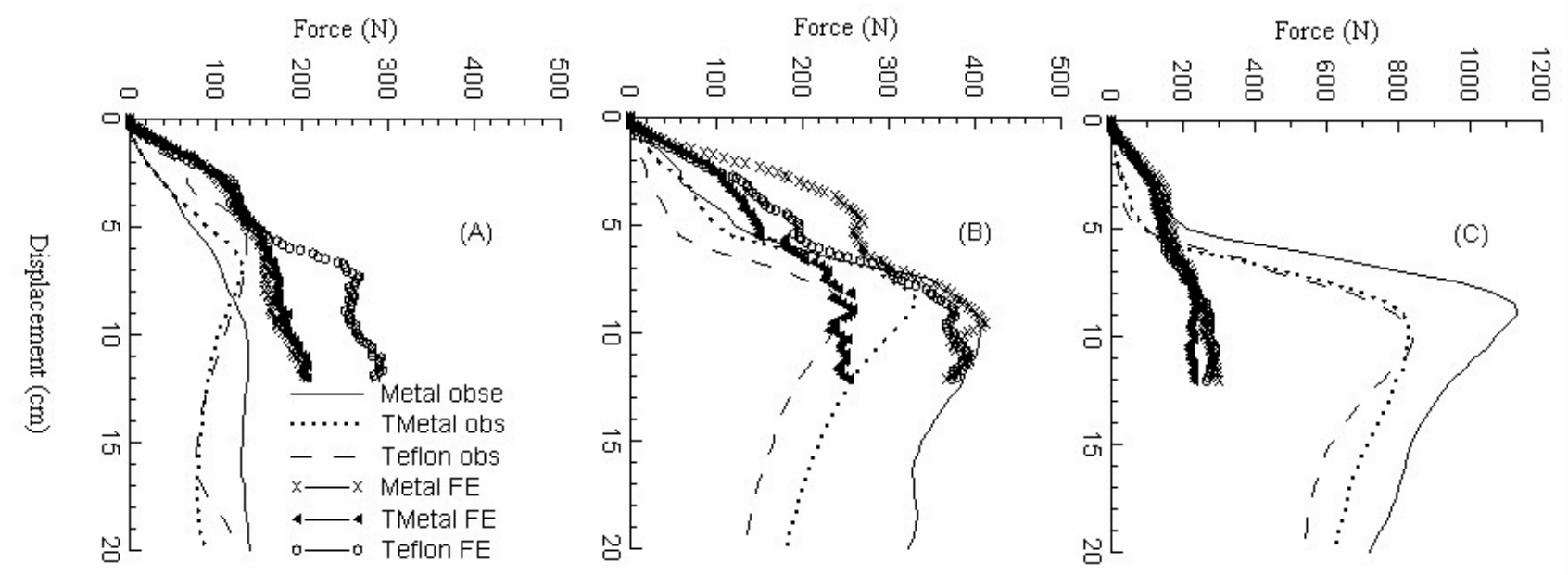

Figure 4. FE predicted (lines with symbols) vs. observed penetration resistance (lines) for soil moisture level II (Dry) and for compaction I (A), compaction II (B) and compaction III (C), and cone material types.
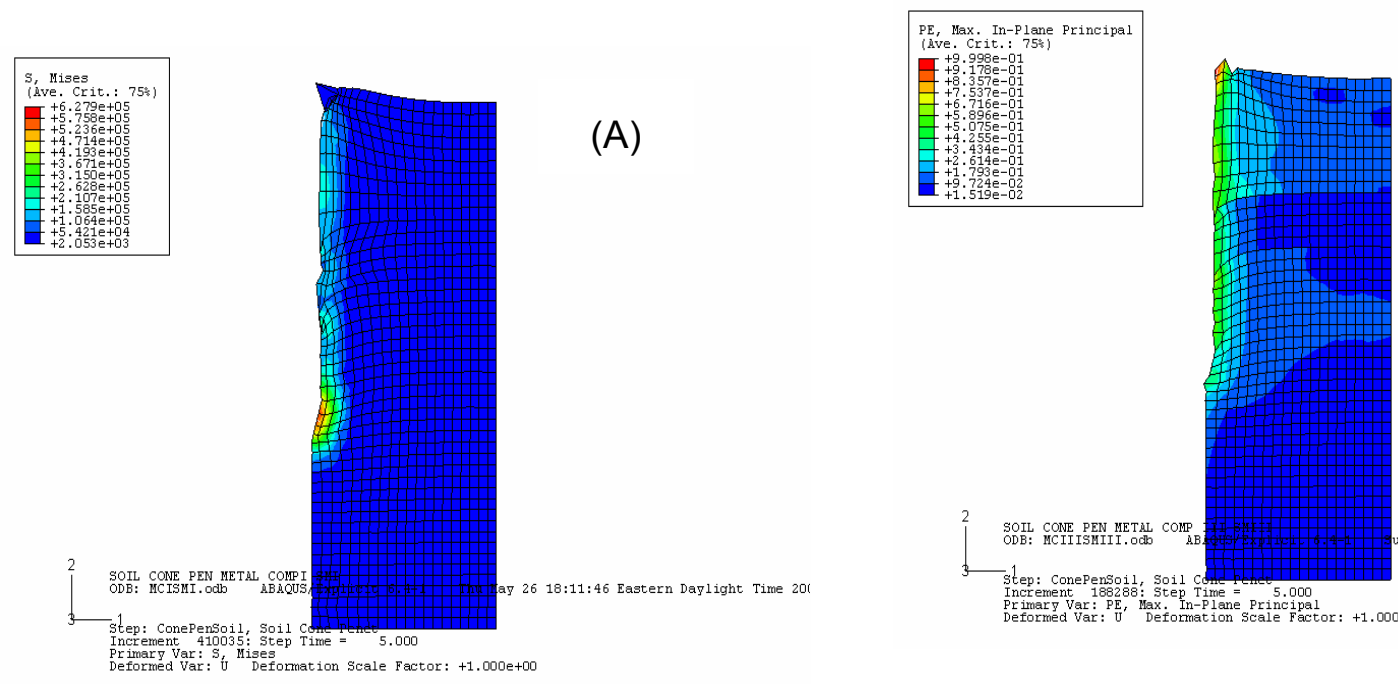

Figure 5. FE analysis results showing von Mises soil stress (MPa) (A) and volumetric plastic soil strain $(B)$ for Norfolk sandy loam soil during cone penetration.

\section{References}

ABAQUS, Version 6.4. 2004. ABAQUS, Inc. U.S.A.

ASAE Standard, 46Ed. 1999a. S313.3. Soil cone penetrometer. St. Joseph, Mich.:ASAE. ASAE Standard, 46Ed. 1999b. EP542. Soil cone penetrometer. St. Joseph, Mich.:ASAE. Bailey, A.C. 2004. Unpublished data. Auburn, Ala.: USDA-ARS National Soil Dynamics Laboratory.

Bailey, A.C. and C. E. Johnson. 1989. A soil compaction model for cylindrical stress states. Transactions of the ASAE 32(3): $822-825$.

Bailey, A.C. and C. E. Johnson. 1996. Soil critical state behavior and the NSDL-AU model. ASAE Paper No. 96-1064. St. Joseph, Mich.: ASAE. 
Batchelor, J. A. 1984. Properties of bin soils. National Tillage Machinery Laboratory, USDAARS, Auburn, AL.

Farrell, D.A. and E.L. Greacen. 1965. Resistance to penetration on fine probes in compressible soil. Division of Soils,CSIRO, Adelaide, Australia.

Foster,Jr. W.A., C.E. Johnson, R.C. Chiroux and T.R. Way. 2005. Finite Element Simulation of Cone Penetration. Applied Mathematics and Computation 162: 735-749.

Grisso, R.D., Jr. 1985. Compaction of agricultural soil by continuous deviatoric stress. Ph.D. Dissertation. Auburn University, AL.

Gill, W.R. and G.E. VandenBerg. 1968. Soil Dynamics in Tillage and Traction. Agriculture Handbook No. 316. USDA-Agricultural Research Service, Washington. D.C.

Johnson, C.E. and A.C. Bailey. 2002. Soil Compaction. In Advances in Soil Dynamics Vol. 2: 155-178. St. Joseph,Mich:ASAE.

Markauskas, D. , R. Kacianauskas, M. Suksta. 2002. Modeling the cone penetration test by the finite element method. Foundation of Civil and Environmental Engineering. No. 2. Poznan University of Technology,Poznan, Poland.

Mouazen, A.M. and H. Ramon. 2002. A numerical -statistical hybrid modeling scheme for evaluation of draught requirements of a subsoiler cutting a sandy loam soil, as affected by moisture content, bulk density and depth. Soil and Tillage Research 63:155-165.

Mulqueen, J., J. V. Stafford, and D.W. Tanner. 1977. Evaluation of penetrometers for measuring soil strength. Journal of Terramechanics. 14: 137-151.

Lunne, T., P.K. Robertson, and J.J.M. Powell. 1997. Cone penetration testing in geotechnical practices. Blackie academic and professional, London, UK.

Perumpral, J.V. 1987. Cone penetrometer applications-A review. Transactions of the ASAE 30(4):939-944.

Raper,R.L. and D.C. Erbach. Effect of variable linear elastic paratemeters on finite element prediction of soil compaction. Transactions of the ASAE 33(3):731-736.

Raper, R. L., D.W. Reaves, J.N. Shaw, E. van Santen, and P.L. Mask. 2004. Site-specific subsoiling benefits for coastal plain soils. $26^{\text {th }}$ Southern Conservation Tillage Conference, Raleigh, NC, June 8-9, 2004.

Rohani, B. and G. Y. Baladi. 1981. Correlation of mobility cone index with fundamental engineering properties of soil. International Society for Terrain-Vehicle Systems. Vol 3:959-990. Alberta,Canada.

Upadhyaya,S.K.,U.A. Rosa and D. Wulfsohn. 2002. Application of the finite element method in agricultural soil mechanics. In Advances in Soil Dynamics Vol. 2: 117-1153. St. Joseph,Mich:ASAE.

Sanglerat, G. 1972. Interpretation of penetration diagrams- theory and practice. Developments in geotechnical engineering. Elsevier publishing company. Amsterdam, The Netherlands.

Susila, E. and R. D. Hryciw. 2003. Large displacement FEM modeling of the cone penetration test (CPT) in normally consolidated soil. Int. J. Numer. Anal. Meth. Vol. 27:585-602.

Yu, H.S. and J.K. Mitchel.1998. Analysis of cone resistance: Review of Methods. Journal of Geotechnical and Geoenvironmental Engineering. Vol. 124:140-149. ASCE. 